\title{
Single tooth implant placement with immediate temporisation: Case report
}

\author{
Gurjeev Kaur ${ }^{1, *}$, Jagadeesh H. G. ${ }^{2}$, Jay Vikram ${ }^{3}$, Dhruv Anand ${ }^{4}$ \\ ${ }^{1}$ Post Graduate Student, ${ }^{2}$ Professor and Head, ${ }^{3}$ Professor, ${ }^{4}$ Assistant Professor, ${ }^{1-4}$ Dept. of Prosthodontics, Crown \& Bridge, \\ School of Dental Sciences, Sharda University, Greater Noida, Uttar Pradesh, India
}

*Corresponding Author:

Email: drsonal2326@gmail.com

\begin{abstract}
Implants are considered to be the best and first treatment options to replace the missing teeth. The goal of implant treatment is to restore the function, aesthetics and comfort of the patient and also the temporisation was done on the same day of implant placement to maintain the soft tissue contours. This article presents a case report on placement of implant in healed socket along with immediate temporisation.
\end{abstract}

Keywords: Missing tooth, Dental implant, Immediate loading, Immediate temporization.

\section{Introduction}

Implant dentistry nowadays is considered to be an integral part of dentistry. The use of dental implants in the esthetic zone has overcome many disadvantages of conventional restorative techniques. That is why implants are considered as an alternative treatment option for replacement of tooth as it restores both the function and aesthetics. ${ }^{2,3}$ Conventionally, after the placement of implant, it is recommended to have 3-6 months of load free healing period for successful osseointegration to occur. But numerous practitioners now advocate immediate loading of implants i.e. the implants were restored following the surgical placement which allow the maintenance of soft tissue contours along with the interdental alveolar contours. ${ }^{1}$

\section{Case Report}

A 18 year old boy presented to the Department of Prosthodontoics, Sharda university with a chief complaint of loss of upper front teeth due to road accident 4 months back. On detailed intra oral examination, patient had missing right maxillary central incisor and with intact left maxillary central incisor and lateral incisor. (Fig. 1) The patient general periodontal condition was healthy.

Patient was wearing a removable partial denture wrt 11 since 4 months and wants durable and fixed alternative to replace missing upper front tooth for aesthetics reasons.

Clinical and Radiographic evaluation revealed adequate alveolar bone in the future implant site. (Fig. 2) So, it was planned to place implants measuring $3.3 \mathrm{x}$ $11.5 \mathrm{~mm}$ in dimension along with immediate temporisation to maintain the emergence profile and to preserve the alveolar bone.

Following local Anaesthesia was administered in the area of missing central incisor. Mid crystal incision was given with releasing incision and full thickness flap was raised and underlying bone was inspected for adequate perfusion. A punch osteotomy was made using a round punch drill in the Centre of edentulous span. A $2 \mathrm{~mm}$ pilot drill was used to make the initial osteotomy till a depth of $11.5 \mathrm{~mm}$. Subsequent drilling was done till diameter of $2.8 \mathrm{~mm}$ and a counter sink was given with $3.0 \mathrm{~mm}$ drill. Implant insertion in the osteotomy site was done using torque ratchet till all threads were submerged into bone and insertion torque of $45 \mathrm{Ncm}$ was achieved. (Fig. 3)

Immediate loading with 15 degree of angulated abutment was done (Fig. 4)and flap was closed using 30 silk suture and impression were made to make check cast and temporary was fabricated using PMMA. It was verified in patients mouth and occlusion adjustments were done and was cemented with temporary cement. (Fig. 5, 6)

Antibiotic (Amoxicillin \& Clavulanic Acid 625 mg, twice daily for 5 days) and Anti-inflammatory (Zerodol SP, thrice daily for 5 days) were prescribed and post-operative instructions were given. The patient was seen post surgically after 1 week for suture removal and no signs of superinfection were noted.

Patient was recalled after 3 months for prosthetic procedures and adequate amount of interdental papilla and the buccal contours were observed similar to the adjacent tooth, the abutment was removed and an impression coping placed, followed by a Poly Vinyl Siloxane impression. The impression coping was removed and abutment was replaced and temporary prosthesis was recemented and shade was also noted. Excess cement was removed and the occlusion was again verified. After 7 days, jig trial was verified and after 5 days, the temporary prosthesis along with abutment was removed and final crew retained crown wrt 11 and access hole was plugged with composite.

The patient was very happy with the final aesthetic and functional outcome. (Fig. 7) 


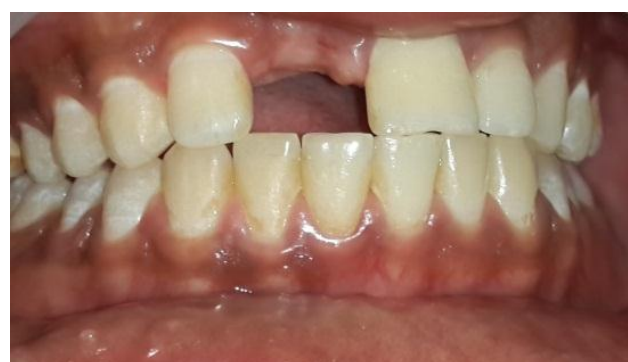

Fig. 1: Intra oral view

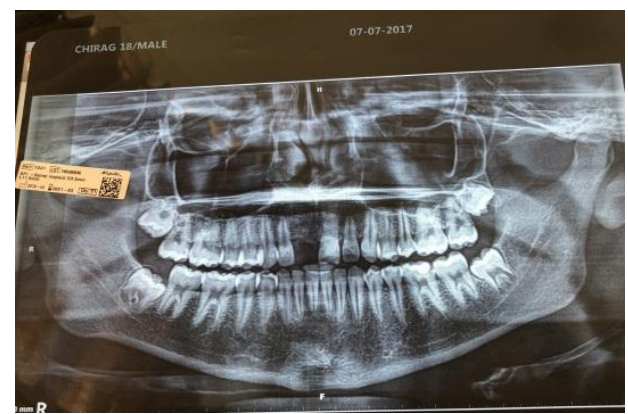

Fig. 2: Pre Op OPG

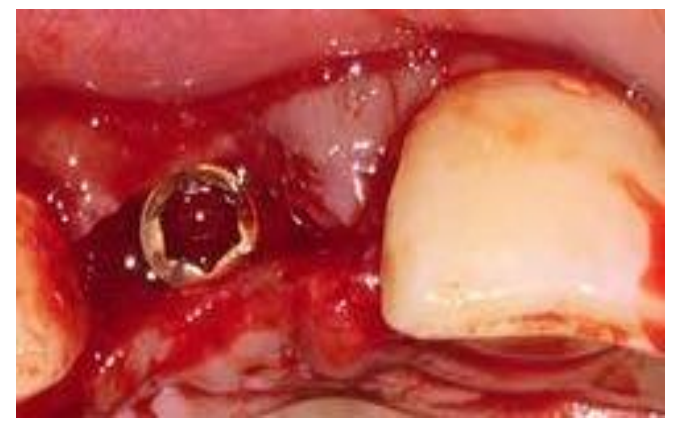

Fig. 3: Implant placed wrt 11

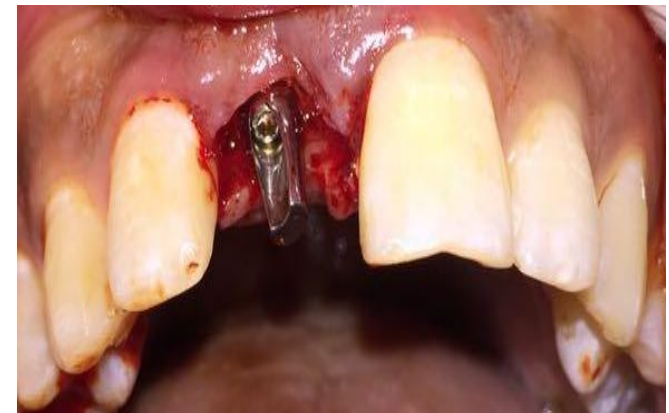

Fig. 4: Immediate loading of implant with angulated abutment

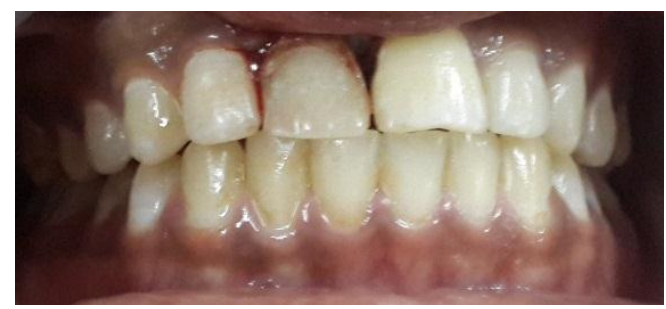

Fig. 5: Temporary prosthesis immediately after implant placement

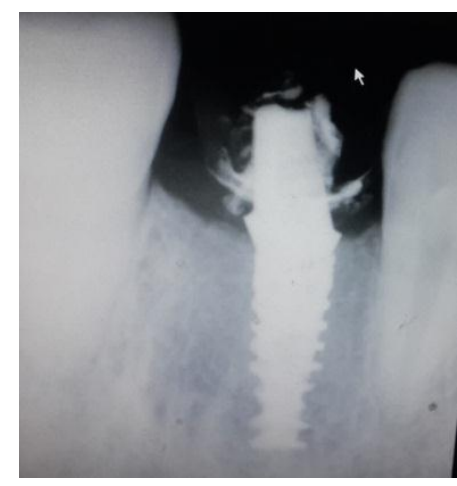

Fig. 6: Post op RVG

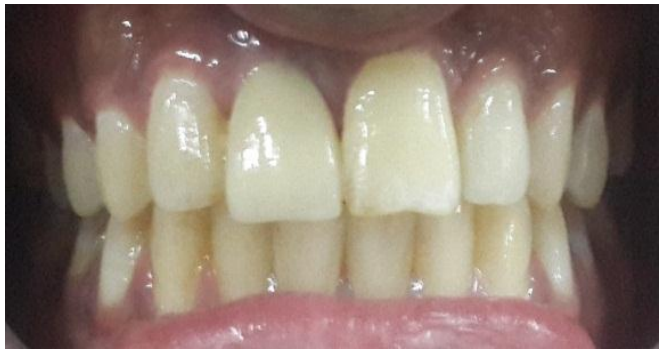

Fig. 7: Final prosthesis

\section{Discussion}

This case report discussed the key concepts of treatment planning, implant surgery, and prosthetic rehabilitation needed to achieve aesthetic success in the maxillary anterior region. The use of dental implants in the maxillary anterior region to replace missing teeth is a viable treatment option. There are many benefits of fixed dental implant-supported prosthetics versus traditional crown and bridge or removable tooth-borne prosthetics. ${ }^{4}$ Successful implant treatment to replace missing teeth in the anterior maxilla requires preoperative planning and a specific surgical plan, and ultimately prostheses are fabricated in consideration of function and soft-tissue support. ${ }^{5}$

\section{Conclusion}

Placing dental implant in the maxillary anterior region requires precise planning, surgery, and prosthetic treatment. This case report has illustrated the steps needed to create ideal aesthetics in the maxillary anterior region. The prosthetic restoration of a dental implant must be ideal to achieve the desired aesthetic result. This case report has discussed the importance of a comprehensive and interdisciplinary approach to treatment planning, surgery, and restoration of dental implants in the maxillary anterior region of the mouth.

\section{References}

1. El Askary AS. Aesthetic considerations in anterior single tooth replacement. Implant Dent 1999,8:61-67.

2. Spielman HP. Influence of the implant position on the aesthetics of the restoration. Pract Periodontics Aesthet Dent. 1996; 8:897-904. 
3. Simeone P, De Paoli C, De Paoli S, Leofreddi G, Sgrò S. Interdisciplinary treatment planning for single-tooth $J$ Esthet Restor Dent. 2007;19(2):79-88.

4. Misch CE The importance of dental implants. Gen Dent. 2001;49:38-45.

5. Tischler M. Dental implants in the esthetic zone. Considerations for form and function. $N Y$ State Dent $J$. 2004;70:22-26.

6. Garber DA. The esthetic dental implant: letting restoration be the guide. J Oral Implantol. 1996;22(1):4550.

7. Sadan A, Blatz MB, Salinas TJ, Block MS. Singleimplant restorations: a contemporary approach for achieving a predictable outcome. J Oral Maxillofac Surg. 2004;62(9 Suppl 2):73-81.

8. 8. Norton M. Single tooth immediate provisional restoration of dental implants: Technique and early results. J Oral Maxillofac Surg. 2004;62:1131-8.
9. Norton M. Single tooth immediate provisional restoration of dental implants: Technique and early results. J Oral Maxillofac Surg. 2004;62:1131-8.

10. Coppel A, Prados JC, Coppel J. Implantes post-extracción: situación actual. Gaceta Dental Sept. 2001;120:80-86.

11. Douglass GL, Merin RL. The immediate dental implant. $J$ California Dent Assoc. 2002;30:362-365.

12. Handelman M. Surgical guidelines for dental implant placement. Br Dent J 2006;201:139-52.

13. Cairo F, Pagliaro C, Nieri M. Soft tissue management at implant sites. J Clin Periodontol 2008;35:163-7.

14. Binon PP. Provisional fixed restorations supported by osseointegrated implants in partially edentulous patients. Int J Oral Maxillofac Implants 1987;2:173-8. 